\title{
LETTERS
}

\section{Referral for medical assistance in dying}

Excellent article. ${ }^{1}$ It seems to me that the College of Physicians and Surgeons of Ontario is trying to bully and force physicians to endorse an ideology with the threat of job loss, calling it a patient access issue.

There is no evidence in Ontario (or any other province without this restrictive policy) that access to medical assistance in dying (MAiD) would or has been curtailed without an effective referral policy. Mandating referral is simply unnecessary. There are many other ways that access to MAiD can be ensured without forcing physicians to choose between their calling and their conscience.

\section{Paul Galessiere MD}

General surgeon, Steinbach Family Medical, Bethesda Primary Care Centre, Steinbach, Man.

- Cite as: CMAJ 2018 June 4;190:E693.

doi: $10.1503 / \mathrm{cmaj} .69261$

\section{Reference}

1. Kelsall D. Physicians are not solely responsible for ensuring access to medical assistance in dying [editorial]. CMAJ 2018; 190:E181.

Competing interests: None declared. 